UNIVERSITATS

KLINIKUm

jena

\title{
Retrospective evaluation of pituitary tumours in a tertiary single care institution
}

\section{Dimitrios Askitis¹, Christof Kloos¹, Wilgard Battefeld¹, Gunter Wolf1 ${ }^{1}$, U. A. Müller}

1: University Hospital Jena, Clinic for Internal Medicine III, Department of Endocrinology and Metabolic Diseases

\section{Introduction- Objective}

Pituitary tumours are nowadays a common incidental finding in the daily clinical pactice. Their prevalence has increased due to more widespread available radiological imaging methods. The majority of epidemiological studies worldwide have shown that most of these tumours are small (microadenomas: diameter $<10 \mathrm{~mm}$ ) and hormonally inactive.

Aim of this retrospective study was the evaluation of all patients with piituitary tumours who were treated in our tertiary department of endocrinology between 1.1.1997-1.11.2014

\section{Patients- Methods}

The study included 215 patients (124 females: 91 males, mean age 50,9 y.) who were treated because of radiologically detectable pituitary tumours. Patients with mild non-drug induced hyperprolactinaemia and without imaging detection of a pituitary tumour were excluded from the study. All patients underwent basal hormonal analysis and testing in order to check for hormonal activity. Pituitary masses were divided into groups concerning their hormonal status and were further classified according to gender, age at diagnosis, tumour size and the development of postoperative pituitary insufficiency when neurosurgical intervention was conducted.

Tab.1: Pituitary tumour type and classification in relation to age and gender

Tumour type

Hormonally inactive

adenomas

Prolactinomas

Cushing's disease

Growth hormone secreting

Craniopharyngeomas

Total

Tab.2: Pituitary tumour type and classification according to tumour size totally and in relation to gender (men/women; $M / W$ )

\begin{tabular}{|l|c|c|c|}
\hline Tumour type & $\begin{array}{c}\text { Mean size } \\
\text { (M/W) }\end{array}$ & $\begin{array}{c}<\mathbf{1 0} \mathbf{~ m m} \\
\text { (microadenoma) } \\
\text { (M/W) }\end{array}$ & $\begin{array}{c}>\mathbf{1 0} \mathbf{~ m m} \\
\text { (macroadenoma) } \\
\text { (M/W) }\end{array}$ \\
\hline Hormonally inactive & $\begin{array}{c}1,8 \\
(2,1 / 1,6)\end{array}$ & $23(8 / 15)$ & $98(51 / 47)$ \\
\hline Prolactinomas & $\begin{array}{c}1,8 \\
(2,3 / 1,6)\end{array}$ & $21(3 / 18)$ & $36(18 / 18)$ \\
\hline Cushing's disease & $\begin{array}{c}1,0 \\
(2,1 / 0,8)\end{array}$ & $12(0 / 12)$ & $4 \quad(1 / 3)$ \\
\hline Growth hormone & $\begin{array}{c}1,8 \\
(2,0 / 1,7)\end{array}$ & $6(3 / 3)$ & $11(5 / 6)$ \\
\hline Secreting & $\begin{array}{c}3,2 \\
(2,9 / 3,8)\end{array}$ & 0 & $4 \quad(2 / 2)$ \\
\hline Craniopharyngeomas & 1,8 & $62(14 / 48)$ & $153(77 / 76)$ \\
\hline
\end{tabular}
Total cohort (mean Male (mean age Female (mean age age at diagnosis) at diagnosis) at diagnosis)

\begin{tabular}{ll|ll|ll}
4 & $(56,0)$ & 2 & $(39,0)$ & 2 & $(73,0)$ \\
\hline & $(5,0)$ & 91 & $(54,0)$ & 124 & $(48,6)$
\end{tabular}

\section{Results}

121 patients had hormonally inactive tumours (non-functioning adenomas; $56,3 \%), 57$ tumours were prolactinomas (26,5\%), 17 growth-hormone secreting adenomas with acromegaly $(7,9 \%), 16 \mathrm{ACTH}$-secreting with manifestation of Cushing's disease $(7,4 \%)$ and 4 craniopharyngiomas $(1,9 \%)$. Nearly all patients with Cushing's disease were females (15/16; 93,8\%). Tumours with size $<1 \mathrm{~cm}$ (microadenomas) were detected in 62 patients $(28,8 \%)$ and $>1 \mathrm{~cm}$ (macroadenomas) in $153(71,2 \%)$ of all cases (rate $1: 2,5)$

The vast majority of microprolactinomas were detected in females $(18 / 21$ $85,7 \%$ ), while the gender distribution of macroprolactinomas was equal. $75 \%$ of ACTH-secreting adenomas were $<10 \mathrm{~mm}$, while $64,7 \%$ of acromegaly patients featured macroadenomas. 98 patients $(45,6 \%)$ were operated (87 via transsphenoidal adenectomy and 11 via transcranial approach), of this group $34 / 90(37,8 \%)$ with hormonally active tumours and $49,6 \%$ of non-functional adenomas. Indications for surgery were an increased risk or manifestation of chiasma syndrome and or manifested clinical symptoms due to hormonal hypersecretion. Immunohistochemical stainings of the hormonally inactive tumours (all macroadenomas) detected 19 gonadotrophic adenomas, 28 null-cell adenomas, 10 adenomas with various focal hormonal expression without clinical relevance, 1 Rathke's cleft cyst, 2 cysts and 1 pituitary lesion because of lymphocytic hypophysitis.

Complete (32 cases $(32,6 \%)$ ) or partial (33 cases $(33,7 \%)$ ) postoperative hypopituarism in minimum 1 pituitary axis was present in 65/98 (66,3\%) of the operated patients. Specifically, the majority of patients with operated inactive tumours (44/60;73,3\%) and ACTH-secreting adenomas (11/14; 78,6\%) developed various grades of pituitary insufficiency, while only $28,5 \%$ of the acromegalic patients featured postoperative hypopituarism.
Tab.3: \% of operated pituitary tumours and development of postoperative pituitary insufficiency

\begin{tabular}{|l|c|c|}
\hline Tumour type & Operation (\%) & $\begin{array}{l}\text { Postoperative pituitary } \\
\text { insufficiency (complete) }\end{array}$ \\
\hline Hormonally inactive & $\begin{array}{l}60 / 121 \\
(49,6 \%)\end{array}$ & $44(22)$ \\
\hline Prolactinomas & $\begin{array}{l}6 / 57 \\
(10,5 \%)\end{array}$ & $3(1)$ \\
\hline Cushing's disease & $\begin{array}{l}14 / 16 \\
(87,5 \%)\end{array}$ & $11(5)$ \\
\hline Growth hormone & $\begin{array}{l}14 / 17 \\
(82,4 \%)\end{array}$ & $3(1)$ \\
\hline secreting & $4 / 4(100 \%)$ & $4(3)$ \\
\hline Craniopharyngeomas & $\begin{array}{l}98 / 215 \\
(45,6 \%)\end{array}$ & $65(32)$ \\
\hline Total & \multicolumn{2}{|}{} \\
\hline
\end{tabular}

\section{Conclusions}

Pituitary adenoma prevalence is rising due to widely available imaging procedures. The majority of the tumours in our cohort were macroadenomas and hormonally inactive. Tumour extirpation via transphenoidal or transcranial adenectomy resulted in functional pituitary impairment in 2/3 of the patients. 